Cluster-assembled cubic zirconia films with tunable and stable nanoscale morphology against thermal annealing

F. Borghi, E. Sogne', C. Lenardi, A. Podestà, M. Merlini, C. Ducati, and P. Milani'

Citation: J. Appl. Phys. 120, 055302 (2016); doi: 10.1063/1.4960441

View online: http://dx.doi.org/10.1063/1.4960441

View Table of Contents: http://aip.scitation.org/toc/jap/120/5

Published by the American Institute of Physics 


\title{
Cluster-assembled cubic zirconia films with tunable and stable nanoscale morphology against thermal annealing
}

\author{
F. Borghi, ${ }^{1}$ E. Sogne,${ }^{1,2, a)}$ C. Lenardi, ${ }^{1}$ A. Podestà, ${ }^{1}$ M. Merlini, ${ }^{3}$ C. Ducati, ${ }^{4}$ and P. Milani ${ }^{1, b)}$ \\ ${ }^{1}$ CIMAINA and Dipartimento di Fisica, Università degli Studi di Milano, via Celoria 16, 20133 Milano, Italy \\ ${ }^{2}$ European School of Molecular Medicine (SEMM), IFOM-IEO, Milano, Italy \\ ${ }^{3}$ Dipartimento di Scienze della Terra "Ardito Desio", Università degli Studi di Milano, via Mangiagalli 32 , \\ 20133 Milano, Italy \\ ${ }^{4}$ Department of Materials Science and Metallurgy, University of Cambridge, 27 Charles Babbage Road, \\ Cambridge CB3 OFS, United Kingdom
}

(Received 15 May 2016; accepted 23 July 2016; published online 5 August 2016)

\begin{abstract}
Nanostructured zirconium dioxide (zirconia) films are very promising for catalysis and biotechnological applications: a precise control of the interfacial properties of the material at different length scales and, in particular, at the nanoscale, is therefore necessary. Here, we present the characterization of cluster-assembled zirconia films produced by supersonic cluster beam deposition possessing cubic structure at room temperature and controlled nanoscale morphology. We characterized the effect of thermal annealing in reducing and oxidizing conditions on the crystalline structure, grain dimensions, and topography. We highlight the mechanisms of film growth and phase transitions, which determine the observed interfacial morphological properties and their resilience against thermal treatments.
\end{abstract} Published by AIP Publishing. [http://dx.doi.org/10.1063/1.4960441]

\section{INTRODUCTION}

Zirconium dioxide $\left(\mathrm{ZrO}_{2}\right)$, also known as zirconia, is a polymorphic material exhibiting three different crystallographic phases for different temperature ranges at normal atmospheric pressure: the monoclinic phase, from room temperature to $1175^{\circ} \mathrm{C}$, the tetragonal phase, from 1175 to $2370^{\circ} \mathrm{C}$, and the cubic phase, from 2370 to $2750^{\circ} \mathrm{C}$ (melting point). ${ }^{1,2}$ Zirconia finds a wide variety of applications for its mechanical strength and toughness, ${ }^{3}$ high chemical resistance, and thermal stability. ${ }^{4} \mathrm{ZrO}_{2}$ films are used for the production of fuel gas sensors, ${ }^{5}$ fuel cells, ${ }^{6,7}$ and in catalytic applications as supports or active phases. ${ }^{8-10}$ The excellent biocompatibility makes also zirconia a material of choice for orthopaedic prosthesis and dental restorative applications. ${ }^{1-14}$

The above mentioned properties are typical of the tetragonal and cubic high-temperature phases: ${ }^{1,12}$ this has stimulated a considerable effort in the characterization of the conditions determining zirconia phase stability and transition. ${ }^{12,15-17}$ The high-temperature phases can be stabilized at room temperature by introducing oxygen deficiencies; this is usually obtained by doping zirconia with divalent $\left(\mathrm{Mg}^{2+}\right.$, $\left.\mathrm{Ca}^{2+}\right)$ and trivalent $\left(\mathrm{Y}^{3+}, \mathrm{Sc}^{3+}\right)$ cationic species. ${ }^{9}$

The phase stability of zirconia polymorphs is substantially different when one considers nanoparticles: in pure $\mathrm{ZrO}_{2}$ nanopowders and nanocrystalline zirconia, the tetragonal phase $\left(\mathrm{t}-\mathrm{ZrO}_{2}\right)$ and the cubic phase $\left(\mathrm{c}-\mathrm{ZrO}_{2}\right)$ are stable at room temperature. ${ }^{18,19} \mathrm{~A}$ critical nanoparticle diameter around $20 \mathrm{~nm}$ has been reported by several authors above

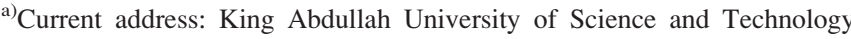
(KAUST), Biological and Environmental Sciences and Engineering (BESE) Division, 23955-6900 Thuwal, Saudi Arabia.

b) Author to whom correspondence should be addressed. Electronic mail: pmilani@mi.infn.it
}

which the monoclinic phase $\left.(\mathrm{m}-\mathrm{ZrO})_{2}\right)$ returns to be the most stable $^{20,21}$ at room temperature.

The mechanism responsible for the stability of $\mathrm{t}-\mathrm{ZrO}_{2}$ and $\mathrm{c}-\mathrm{ZrO}_{2}$ nanocrystals at room temperature has not yet been unambiguously identified: several authors have proposed the differences in surface energy between the different phases, ${ }^{22-24}$ the influence of anionic impurities, oxygen vacancies, ${ }^{25}$ the influence of lattice strain, the influence of lattice defects, and/or water vapour. ${ }^{26}$ Recently, it has been shown that nanocrystalline $\mathrm{t}-\mathrm{ZrO}_{2}$ can be truly thermodynamically more stable than $\mathrm{m}-\mathrm{ZrO}_{2}$ in air below $1200{ }^{\circ} \mathrm{C}$ in the absence of coarsening, ${ }^{27}$ offering further support to the thermodynamic surface energy hypothesis.

For applications in biotechnology and catalysis, the use of nanostructured zirconia films is of particular interest not only for the stabilization of the tetragonal and cubic phases. Parameters such as active surface area, surface roughness, and substrate topography are also critical for cell culturing ${ }^{28}$ or for proteins and enzyme adsorption; ${ }^{29}$ high surface area has significant advantage in catalysing gas reactions due to the increased adsorption capacity, and can often provide more active sites thus giving higher catalytic activity. ${ }^{30}$ It is thus of primary importance to develop fabrication strategies for nanostructured zirconia films able to control not only the structure, phase, and dimensions of the individual nanoparticles, but also their assembling towards the intelligent design of properties such as specific area, micro and nanoscale porosity, and surface corrugation, that must be resilient against thermal treatments and annealing.

Different methods have been reported for the synthesis of nanostructured zirconia films: sol-gel, spray pyrolysis, micro-wave plasma processes, sputtering, non-hydrolytic thermal decomposition, and ion beam assisted deposition technique (IBAD). ${ }^{31-34}$ These approaches concentrate on the 
crystalline structure and thermal stability of the films; no systematic investigation on the nanoscale structure and topography and on their reproducibility, thermal stability and quantitative control have been reported so far. Moreover, conventional production and processing methods, based on solid state or wet chemistry, are not often suitable for the integration with batch micro-fabrication technology, and despite the high efficiency and low cost of these techniques, it is difficult to obtain a reproducible and quantitative control of rough surfaces at the nanoscale.

Recently, we reported that nanostructured zirconia films can be fabricated by depositing neutral zirconia clusters produced in the gas phase and accelerated on a substrate by a supersonic expansion; this approach is called supersonic cluster beam deposition (SCBD). ${ }^{28}$ The use of supersonic expansions instead of effusive beams, as in standard cluster beam deposition, makes it possible the production of intense and highly collimated nanoparticle beams. ${ }^{35}$ In SCBD, neutral clusters are accelerated in a carrier gas by the supersonic expansion; electrostatically accelerated ion clusters are not used therefore to assemble the nanostructured film. ${ }^{36}$

Here, we present the production of cluster-assembled zirconia films with cubic structure at room temperature and with controlled nanoscale morphology. We characterized the effect of thermal annealing in reducing and oxidizing conditions (temperature range: from room temperature to $1000^{\circ} \mathrm{C}$ ) on the crystalline structure, grain dimensions, and topography, highlighting the mechanisms of film growth and phase transition, which determine the observed interfacial morphological properties and their resilience against thermal treatments.

\section{MATERIALS AND METHODS}

\section{Deposition of $n s-\mathrm{ZrO}_{x}$ thin films}

Nanostructured zirconia $\left(\mathrm{ns}-\mathrm{ZrO}_{\mathrm{x}}\right.$ ) thin films were produced using a supersonic cluster beam deposition ${ }^{35,37}$ apparatus equipped with a Pulsed Micro-plasma Cluster Source 38,39 $^{3}$ (PMCS). Details on the deposition technique are provided elsewhere, ${ }^{37,40}$ here, we summarize the most important aspects for the engineering of film nanostructure. The operation of the PMCS is based on the ablation of a zirconium rod by a pulsed argon plasma jet, ignited by an electric discharge. The ablated species thermalize in the quenching inert gas and condense to form clusters. The mixture of clusters and inert gas is then extracted into an expansion chamber through a nozzle and forms a seeded supersonic beam. ${ }^{40}$ Clusters carried by the seeded beam are collected by a substrate placed on a manipulator and perpendicularly intersecting the beam trajectory. The deposition takes place in a second chamber separated by the expansion one by a skimmer. The clusters kinetic energy is low enough to avoid fragmentation, and hence, a cluster-assembled nanostructured film is grown. Zr clusters partially oxidize in the cluster source and in the deposition chamber due to the presence of oxygen traces; oxidation further proceeds upon exposure to air, resulting in a clusterassembled $\mathrm{ZrO}_{\mathrm{x}}(\mathrm{x} \leq 2)$ film.

Five different $n s-\mathrm{ZrO}_{\mathrm{x}}$ batches have been investigated; they are characterized by thickness in the range $50-570 \mathrm{~nm}$ and roughness $\mathrm{Rq}$ ranging from 15 to $40 \mathrm{~nm}$ (see below).
Two ns- $\mathrm{ZrO}_{\mathrm{x}}$ films with thickness of about $150 \mathrm{~nm}$ have been analyzed for determining the film stoichiometry via photoelectron spectroscopy (XPS). Cluster-assembled films directly deposited on support grids have been used for transmission electron microscopy (TEM) characterization. The samples for X-ray powder diffraction (XRPD) have been prepared by scratching pristine deposited films and then putting the obtained powder in a quartz capillary.

\section{Characterization of the surface morphology of $n s-\mathrm{ZrO}_{x}$ films by atomic force microscopy}

We have characterized the surface morphology of $n s-\mathrm{ZrO}_{\mathrm{x}}$ films by Atomic Force Microscopy (Multimode Nanoscope IV by Veeco) in tapping mode, with singlecrystal silicon tips with a nominal radius of curvature in the range $5-10 \mathrm{~nm}$ and cantilever resonance frequency of about $300 \mathrm{kHz}$. We acquired several $2 \mu \mathrm{m} \times 1 \mu \mathrm{m}$ images for each sample with scan rates of $1.5-2 \mathrm{~Hz}$. Sampling resolution was $2048 \times 512$ points. Images were flattened by line-by-line subtraction of first and second order polynomials in order to remove artifacts due to sample tilt and scanner bow. From the images, we have calculated the root-mean-square (RMS) surface roughness $\mathrm{Rq}$ of the samples as the standard deviation of surface heights. The film thickness was calculated by scanning a region of the film, where a sharp step was produced by masking the substrate during cluster deposition.

We investigated also the evolution of the surface morphology at increasing annealing temperatures; in particular, we considered five different temperatures in the interval from room temperature to $800{ }^{\circ} \mathrm{C}$. Samples were thermally annealed in air using an oven brought at the final temperatures of $250-400-600-800^{\circ} \mathrm{C}$, respectively, applying a temperature ramp of $50^{\circ} \mathrm{C}$ in $5 \mathrm{~min}$, and maintaining the target temperatures constant for $2 \mathrm{~h}$.

Quantitative granulometry characterization consists typically in the identification of the grains map and, as a further step, in the statistical evaluation of suitable geometrical parameters describing the granularity of the surface. In order to determine the distribution of the values of the equivalent radius of surface grains, we defined operatively the surface grains as the connected domains in the topographic map having well-defined local curvatures and curvature signs. ${ }^{41,42}$ Grain boundaries are indeed characterized by sudden discontinuities of both the mean $(\mathrm{H})$ and the Gaussian $(\mathrm{K})$ local curvatures, defined as:

$$
\begin{gathered}
\mathrm{H}=\frac{1}{2}\left(\frac{1}{R_{1}}+\frac{1}{R_{2}}\right) \\
\mathrm{K}=\frac{1}{R_{1} R_{2}},
\end{gathered}
$$

where $R_{1}$ and $R_{2}$ are the principal curvature radii. ${ }^{41,42}$ Logical conditions of the form, $\mathrm{H}>0, \mathrm{~K}>0, \mathrm{H}, \mathrm{K}, \mathrm{R}_{1}, \mathrm{R}_{2}$ finite, effectively segment the topographic map into connected domains, defining the grains map. Figs. 1(a) and 1(b) show typical three-dimensional and top-views of a ns- $\mathrm{ZrO}_{\mathrm{x}}$ surface, where the morphological basic units (the grains) are clearly visible. Fig. 1(c) shows the corresponding binary 
(a)
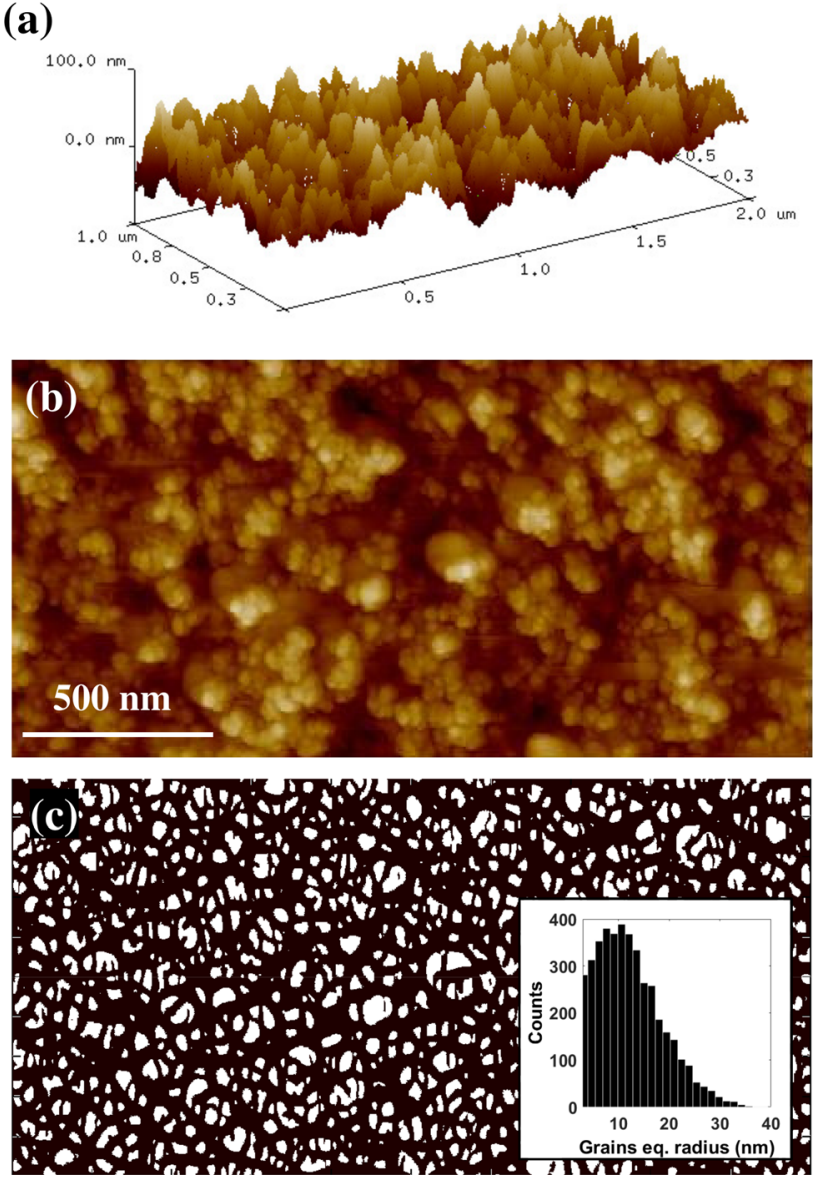

FIG. 1. (a) and (b) Three-dimensional and top-views of a representative AFM topographic map of a ns- $\mathrm{ZrO}_{x}$ film with thickness $168 \mathrm{~nm}$. (c) The grain binary mask calculated as described in the main text (using a smoothing kernel size of $8.4 \mathrm{~nm}$ ). The inset in (c) shows a representative distribution of equivalent radius values.

grain mask, obtained according to the described segmentation procedure. The equivalent radius of each grain defined by the binary mask is calculated under the assumption of grains possessing a circular section: $R_{e q}=\sqrt{\text { proj.area } / \pi}$. The equivalent diameter, in comparison with diffraction data, is twice the equivalent radius. For each sample, we therefore obtain the cumulative distribution of grain radii (a representative distribution is shown in the inset of Fig. 1(c)); median values and median absolute deviations (MADs) are calculated from these distributions.

Tip-sample convolution effects are known to affect the apparent lateral dimensions of surface grains, typically increasing the lateral width of objects. ${ }^{43}$ The determined values of the equivalent grain radii are therefore not extremely accurate; nevertheless, the relative comparison of the mean (median) values among different samples is possible and meaningful, because convolution effects are supposed to be similar.

\section{TEM and $\mathrm{x}$-ray analysis of $\mathrm{ns}-\mathrm{ZrO}_{\mathbf{x}}$ films}

The nanostructure of $\mathrm{ZrO}_{\mathrm{x}}$ films was characterized by high-resolution transmission electron microscopy (HRTEM) using a FEI Tecnai F20 microscope operated at $200 \mathrm{kV}$.
The X-ray powder diffraction analysis (XRPD) measurements were performed at the synchrotron light source facility ELETTRA in Trieste (Italy) at the Materials Characterization by X-ray diffraction beamline (MCX) in order to determine the thermal expansion and structural evolution up to $1000^{\circ} \mathrm{C}$, using the monochromatic radiation ( $\lambda=0.8270 \AA$ ) and the set up described in Refs. 44 and 45 . The capillary containing the cluster-assembled zirconia was inserted into a closed furnace (for accurate temperature control in the range $25-1000^{\circ} \mathrm{C}$ ) and sealed in order to be switched from vacuum to air or inert gas $\left(\mathrm{N}_{2}\right)$ atmospheres. Thermal annealing of the film was performed with a ramp of $50{ }^{\circ} \mathrm{C}$ in $5 \mathrm{~min}$ and then heating the sample at fixed temperature for $20 \mathrm{~min}$. Two sets of measurements were performed, one in vacuum and the other in air. Diffraction signals were collected by a translating curved (cylindrical) imaging plate detector, to assure a constant sample-detector distance and avoid geometrical corrections for intensity. Raw data (pixel vs. intensity) extracted with Fit2D software ${ }^{46}$ were converted into an angle/intensity histogram by a preliminary calibration performed with the NIST standard Si powder. Rietveld analysis of converted spectra was performed with GSAS software. ${ }^{47}$ The crystallite sizes were calculated by fitting the whole XRPD spectrum.

As-deposited $\mathrm{ns}^{-} \mathrm{ZrO}_{\mathrm{x}}$ films were characterized in a UHV apparatus Leybold LHS 10/12 equipped with a hemispherical electron analyzer and conventional X-ray source (Al $\mathrm{K} \alpha=1486.7 \mathrm{eV}$ ). The high-resolution spectra were acquired in constant pass-energy mode $\mathrm{E}_{\text {pass }}=30 \mathrm{eV}$. The overall energy resolution was $1.0 \mathrm{eV}$. The pressure in the experimental chamber during experiments was below $1 \times 10^{-9}$ mbar. All spectra are referenced to the Fermi level, and the binding energy scale is calibrated via the $\mathrm{Au} 4 \mathrm{f}_{5 / 2}$ core level line (located at $88.5 \mathrm{eV}$ ) of a clean polycrystalline Au sample. No charging effects on the samples under investigation were observed during all the measurements. The line shapes were fitted with mixed singlets obtained by a linear combination of a Gaussian and a Lorentzian profiles sited on a Shirley background.

\section{RESULTS AND DISCUSSION}

\section{As-deposited film structure and nanoscale morphology}

Figs. 2(a) and 2(b) show TEM micrographs of a typical cluster-assembled zirconia film: the elemental building blocks are crystalline nanoparticles.

The analysis of the particle size distribution from TEM images provides an average particle diameter of $6.0 \pm 1.7 \mathrm{~nm}$. The fast Fourier transform (FFT) of the lattice is compatible with the pattern of the cubic phase $(\mathrm{a}=4.9250 \AA)$. The quantitative elemental analysis made by XPS shows that asdeposited zirconia is sub-stoichiometric $\left(\mathrm{ZrO}_{\mathrm{x}}\right.$, with $\left.\mathrm{x}=1.9\right)$. The cubic phase of the nanocrystals is confirmed by the XRPD pattern (Fig. 3); within the limit of the experimental resolution, the structural Rietveld fit is compatible with zirconia in cubic phase with a refined unit cell parameter $\mathrm{a}=5.1253 \pm 0.0005 \AA$. 

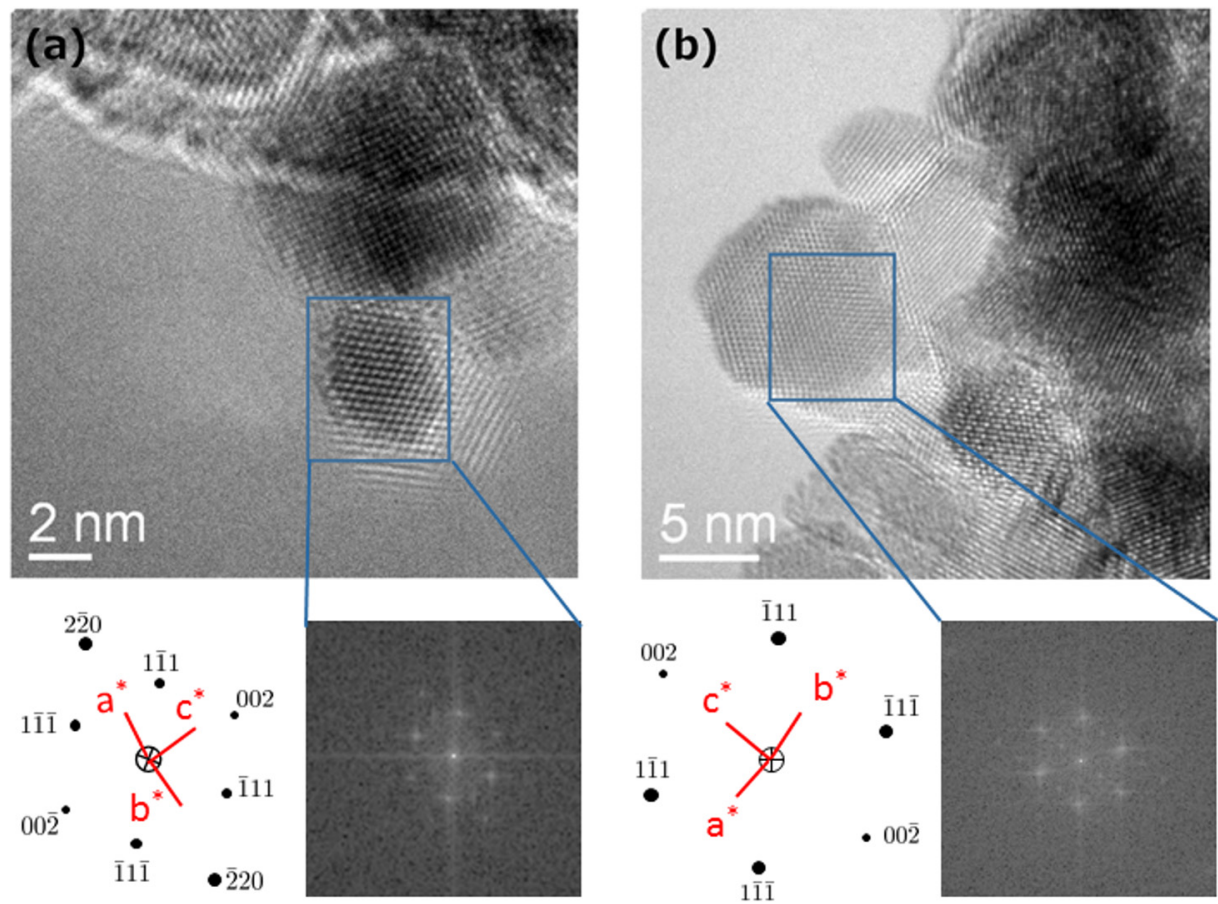

FIG. 2. (a) and (b) Representative TEM images of as-deposited ns- $\mathrm{ZrO}_{\mathrm{x}}$, with nanocrystals and corresponding FFTs highlighted. The obtained lattice spacings are $\mathrm{d}_{111}=0.284 \mathrm{~nm}$ and $\mathrm{d}_{002}=0.246 \mathrm{~nm}$, respectively.
Figs. 1(a) and 1(b) highlight the typical morphology of ns- $\mathrm{ZrO}_{x}$ films produced by SCBD, characterized by high specific area, roughness, and porosity at the nano scale. ${ }^{48}$

As it is well known for evolving growing interfaces, surface roughness, specific area, as well as the lateral dimension of the largest morphological features (the correlation length) increase as time and thickness increase, according to simple scaling laws. ${ }^{49,50}$ The characterization of the scaling exponents allows therefore predicting and controlling the evolution of the surface morphology of nanostructured materials. ${ }^{48}$

We quantitatively characterized the evolution of surface nanoscale roughness with increasing film thickness at room temperature. The analysis of AFM topographic maps shows that the relationship between RMS roughness $\mathrm{Rq}$ and film thickness $\mathrm{h}$ is governed by the power law $\mathrm{R}_{\mathrm{q}} \sim \mathrm{h}^{\beta}$ (Fig. 4), where $\beta$ is the growth exponent. ${ }^{49}$ The value of $\beta$ is obtained by a linear regression of the experimental $\mathrm{Rq}$ vs $\mathrm{h}$ curve in a

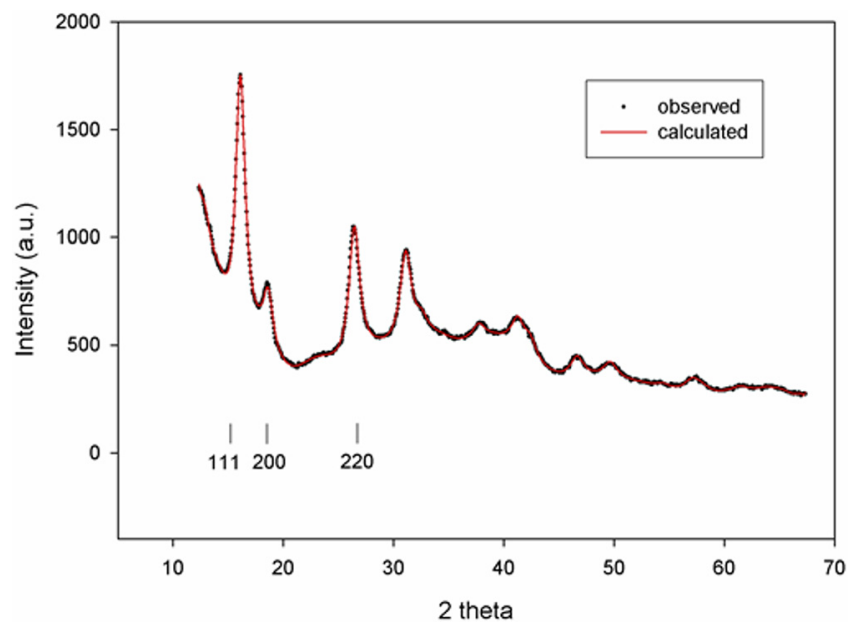

FIG. 3. X-ray powder diffraction pattern of an as-deposited $n s-\mathrm{ZrO}_{\mathrm{x}}$ film. The experimental and simulated diffraction data are plotted. The most intense diffraction peaks are labelled with Miller indices. $\log -\log$ plot. According to our data, $\beta=0.368 \pm 0.001$ for $n s-\mathrm{ZrO}_{\mathrm{x}}$ films, a value typical of evolving interfaces in the ballistic deposition regime, ${ }^{48-50}$ where incoming particles stick on the substrate upon landing without significant mobility. A similar value of the growth exponent $\beta$ was obtained for cluster-assembled nanostructured titania films $\left(\mathrm{ns}-\mathrm{TiO}_{2}\right)$ produced by $\operatorname{SCBD}\left(\beta_{\mathrm{ns}-\mathrm{TiO} 2}=0.380 \pm 0.040\right){ }^{48}$

In order to correlate the evolution of the surface morphological properties with coalescence and phase transition phenomena induced by the thermal annealing process, we have performed surface granulometry studies based on AFM topographic maps. We have focused our attention on the distribution of grain radius values and on their median value, in order to correlate these data to the average crystallite size measured by X-ray diffraction.

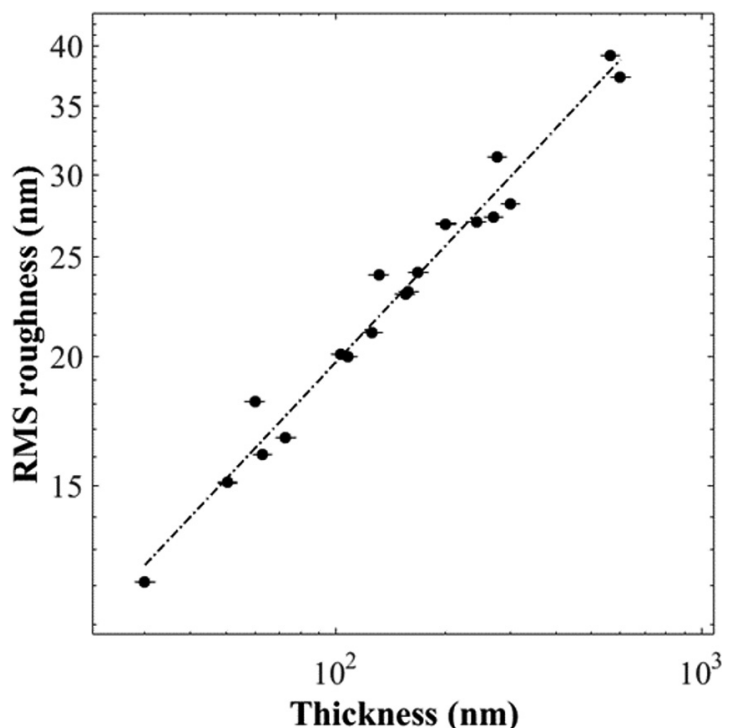

FIG. 4. Evolution of roughness Rq with thickness in $\log -\log$ scale for as-deposited ns- $\mathrm{ZrO}_{\mathrm{x}}$ films. 


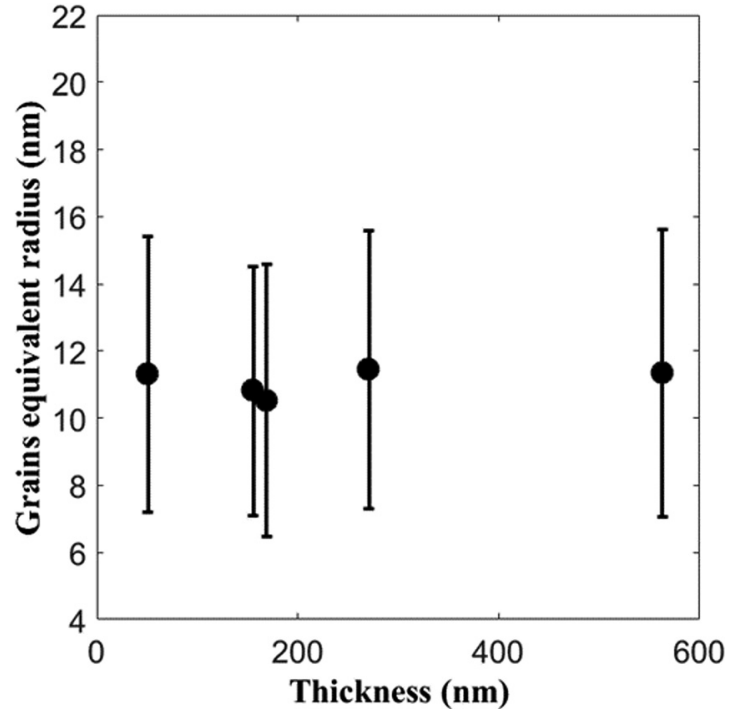

FIG. 5. Evolution of the grain equivalent radius with the thickness for as-deposited $\mathrm{ns}-\mathrm{ZrO}_{\mathrm{x}}$ films.

In Fig. 5, the median values of the grain equivalent radius of $n s-\mathrm{ZrO}_{\mathrm{x}}$ films are reported as a function of the film thickness. The median grain size at room temperature is approximately constant (within less than $1 \mathrm{~nm}$ ) across the whole thickness range, with an average value $R_{e q}^{R T}=11.1 \pm 4.1 \mathrm{~nm}$ (or an average median diameter $D_{e q}^{R T}=22.2 \pm 8.2 \mathrm{~nm}$ ). It should be noted that the surface features (the surface grains) characterized by AFM likely result from the aggregation/coalescence of the deposited clusters/crystallites; the AFM diameter is therefore typically larger than the crystallite size determined by TEM or X-ray diffraction, as reported in the next paragraphs.

\section{Crystalline structure evolution upon thermal annealing}

We performed the annealing experiments for XRPD both in air and in low vacuum (pressure $\sim 10^{-3}$ mbar), in order to assess the role of oxygen in the phase transformation and in the evolution of nanocrystal size. The Rietveld analysis of the X-ray diffraction patterns allowed the estimation of the phase fraction evolution of $\mathrm{ZrO}_{\mathrm{x}}$ polymorphs as a function of temperature. Fig. 6 reports the fractions of the cubic

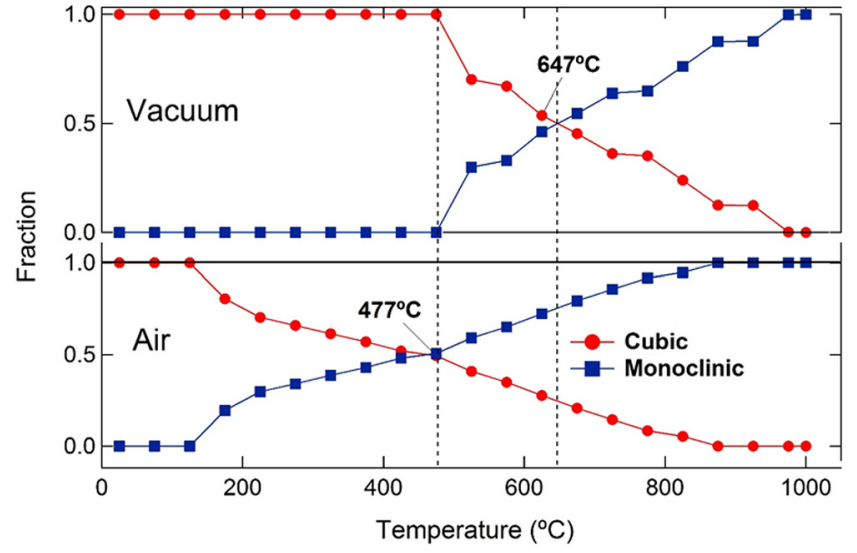

FIG. 6. Phase fraction evolution as function of temperature of cubic and monoclinic $\mathrm{ZrO}_{\mathrm{x}}$ as determined by X-ray diffraction analysis with Rietveld method.

and monoclinic phases as a function of the annealing temperature.

The top panel shows the behaviour in vacuum (reducing environment), whereas the bottom one in air (oxidizing environment). As the temperature increases, we observe the appearance of the monoclinic phase and the decrease of the cubic phase. The arising of the stable phase takes place at $190^{\circ} \mathrm{C}$ and $480^{\circ} \mathrm{C}$ in air and vacuum, respectively. The transformation rate appears to be slower in the case of vacuum condition, in fact the presence of the $50 \%$ of each fraction happens at $475^{\circ} \mathrm{C}$ and $645^{\circ} \mathrm{C}$ in air and vacuum, respectively, and the phase transformation is completed at $875^{\circ} \mathrm{C}$ in air and at $975^{\circ} \mathrm{C}$ in vacuum. Although the same thermal treatment is operated in air and vacuum, the phase transition follows different kinetics. Thus, even if the data have been obtained following the same annealing protocol, it can be argued that the oxygen has a fundamental role in the phase change as well as in the aggregation of nanocrystals. ${ }^{25,51,52}$

\section{Evolution of grain size and film morphology with annealing temperature}

Fig. 7 shows the nanocrystal average crystallite size (diameter) of the cubic and monoclinic phases as a function of the annealing temperature.
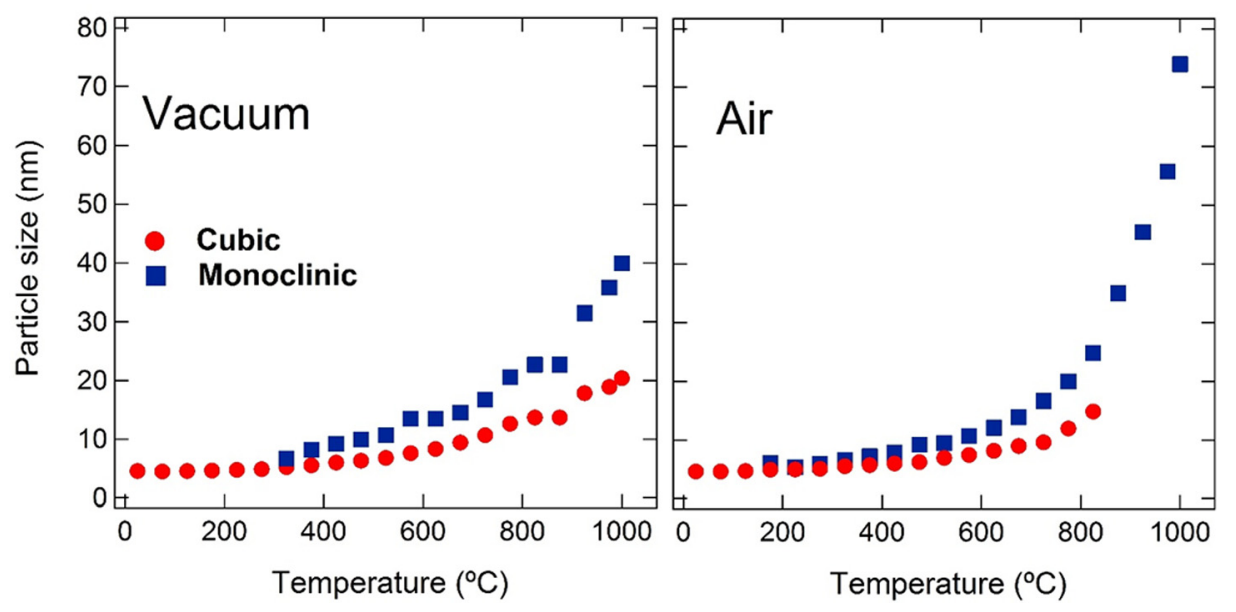

FIG. 7. Average crystallite size (diameter) of $\mathrm{ZrO}_{\mathrm{x}}$ polymorphs as determined by full profile $\mathrm{X}$-ray diffraction pattern fit. 
The nanocrystals in the cubic phase grow up to $18-20 \mathrm{~nm}$ in diameter in both cases, whereas the nanocrystals in monoclinic phase keep on growing. From Fig. 7, it can also be observed as the annealing in oxidizing environment favours the nanocrystal growth, reaching at about $1000^{\circ} \mathrm{C}$, a size doubled $(\sim 80 \mathrm{~nm})$ with respect to the vacuum case $(\sim 40 \mathrm{~nm})$.

Annealing up to $250^{\circ} \mathrm{C}$ causes a little growth of nanoparticles, probably due to the complete crystallization of
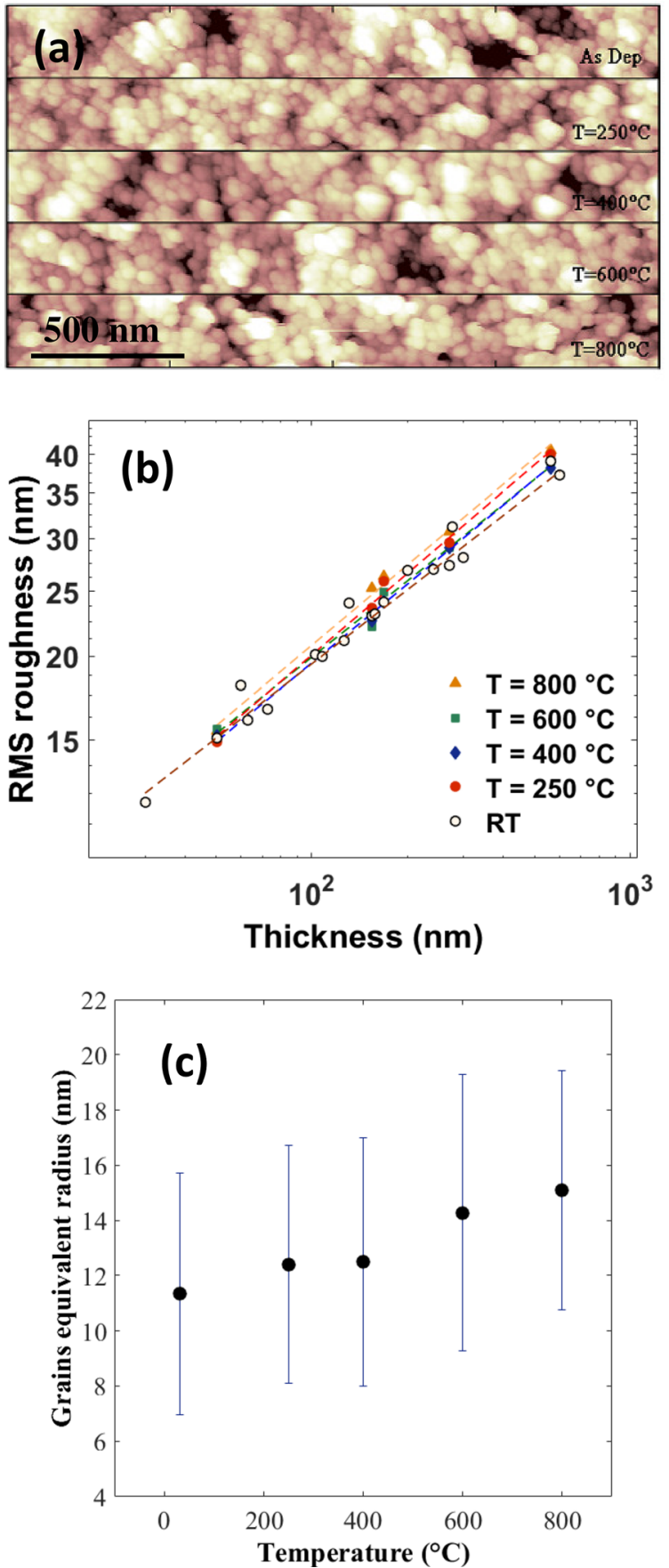

FIG. 8. (a) Topographic image built up by juxtaposition of stripes of topographic maps from the same $150 \mathrm{~nm}$-thick $n s-\mathrm{ZrO}_{\mathrm{x}}$ sample annealed at increasing temperatures from top to bottom ( $\mathrm{z}$ scale ranges from -50 to $50 \mathrm{~nm}$ ). (b) Scaling of the RMS roughness with sample thickness of the as deposited $\mathrm{ZrO}_{\mathrm{x}}$ samples and of the annealed samples at $250^{\circ} \mathrm{C}, 400^{\circ} \mathrm{C}$, $600^{\circ} \mathrm{C}$, and $800^{\circ} \mathrm{C}$ in air, respectively. (c) Evolution of the grain sizes with the annealing temperatures in air, depending on the roughness of the nanostructured zirconia surface. the smaller clusters from the amorphous-to-cubic phase. Successive thermal annealing at $400{ }^{\circ} \mathrm{C}$ and $600{ }^{\circ} \mathrm{C}$ promotes the transition from cubic to monoclinic phase, which determines further growth of the grain size. The XRPD analysis shows that the phase transition from cubic to monoclinic phase in air correlates with the growth of crystalline grains. During annealing, cubic nanocrystals coarsen and when their size reaches a critical value, they transform to stable monoclinic phase. ${ }^{22,32}$ This behavior has been described by the critical-nuclear-size model $;{ }^{53-55}$ according to this model, the monoclinic crystallites cannot grow until the nucleus size of this phase reaches a critical value; this requires the agglomeration of fine-grained cubic particles into larger ones. The growth of cubic nanocrystals beyond the critical size is energetically not favorable since cubic phase has a higher total energy compared to monoclinic one. ${ }^{56,57}$

In Fig. 8(a), we show a $2 \mu \mathrm{m} \times 1 \mu \mathrm{m}$ composite AFM image obtained by juxtaposing narrow stripes of topographic maps of the same $150 \mathrm{~nm}$-thick ns- $\mathrm{ZrO}_{\mathrm{x}}$ sample annealed at different temperatures.

The surface morphology of ns- $\mathrm{ZrO}_{\mathrm{x}}$ appears to be stable against large variation of the annealing temperature, up to $800^{\circ} \mathrm{C}$. No evident surface reorganization/aggregation/ coalescence phenomena are observed. We reported only moderate changes of the RMS roughness (20\%-30\%) induced by thermal annealing, likely due to the increased dimensions of crystallite reported in Fig. $7 .{ }^{31}$ Remarkably, as shown in Fig. 8(b), the growth exponent $\beta$ remains approximately constant across the whole temperature range (varying between 0.380 and 0.406). In Fig. 8(c), we report the evolution of the equivalent grain radius $\mathrm{R}_{\mathrm{eq}}$ measured by AFM of the thickest $n s-\mathrm{ZrO}_{\mathrm{x}}$ sample, as a function of the annealing temperature. Although we observe a bland evolution (increase) of the surface grain size (the equivalent diameter changes from 22 to $30 \mathrm{~nm}$ ), the growth of surface features remains well constrained below the $100 \mathrm{~nm}$.

Our data clearly show that cluster-assembled films deposited by SCBD preserve their truly nanostructured nature also after strong thermal treatments. The surface morphology and structure of these films keep memory of the properties of the nanometer-sized building blocks used to assemble them, this memory-effect being strong and highly resilient with respect to high-temperature annealing processes.

\section{CONCLUSIONS}

We have produced cluster-assembled zirconia films by Supersonic Cluster Beam Deposition and characterized the crystalline structure, grain dimensions, and surface topography of these films over a wide temperature range, from room temperature to $1000^{\circ} \mathrm{C}$. We summarize here the main results obtained and shortly comment on their relevance.

(1) SCBD allows producing nanostructured zirconia films on a variety of substrates with stable cubic phase at room temperature (and up to $190^{\circ} \mathrm{C}$ and $480^{\circ} \mathrm{C}$ in oxidizing and reducing atmosphere, respectively), with no need for stabilizing procedures such as doping with multi-valent cations. 
(2) The surface morphology and structure of $n s-\mathrm{ZrO}_{2}$ films are highly resilient with respect to high-temperature annealing processes.

(3) Even at the highest temperatures, ns- $\mathrm{ZrO}_{2}$ films possess a truly and persistent nanostructured character, inherited by the nanometer-sized building blocks and preserved by the low-energy deposition regime typical of SCBD.

(4) SCBD allows depositing nanostructured zirconia films with a precise and quantitative control on nanoscale morphology and roughness exploiting simple scaling laws typical of the ballistic deposition regime of clusters. In particular, surface topography can be designed by controlling the film thickness during the deposition process.

(5) Thermal annealing in reducing and oxidizing conditions affects the crystalline structure, grain dimensions, and surface topography of ns- $\mathrm{ZrO}_{2}$ films. In particular, the presence of oxygen vacancies determines the stability of the cubic phase and hinders the growth of nanocrystalline grains even at relatively high temperatures.

Overall, SCBD makes it possible to produce nanostructured zirconia interfaces with stable cubic phase at room temperature, and with controlled phase and topography in high-temperature conditions. $\mathrm{Ns}-\mathrm{ZrO}_{2}$ produced by SCBD is therefore a very promising material for demanding biotechnological and catalytic applications.

\section{ACKNOWLEDGMENTS}

This work has been supported by the Italian Ministry of University and Research, MIUR, through the "National Funding for Basic Research" (FIRB) action; project FIRB RBA-P11AYN "Oxides at the nanoscale: functionalities and applications." The Elettra Synchrotron Radiation Facility is acknowledged for provision of beam time, and Dr. A. Lausi and Dr. J. Plaiser for assistance during synchrotron experiments at MCX beamline.

${ }^{1}$ P. M. Kelly and L. R. Francis Rose, Prog. Mater. Sci. 47, 463 (2002).

${ }^{2}$ J. Chevalier, L. Gremillard, A. V. Virkar, and D. R. Clarke, J. Am. Ceram. Soc. 92, 1901 (2009).

${ }^{3}$ C. Piconi and G. Maccauro, Biomaterials 20, 1 (1999).

${ }^{4}$ J. Duval, J. Lyklema, J. M. Kleijn, and H. P. van Leeuwen, Langmuir 17, 7573 (2001).

${ }^{5}$ K. Tanabe and T. Yamaguchi, Catal. Today 20, 185 (1994).

${ }^{6}$ C.-C. Chao, C.-M. Hsu, Y. Cui, and F. B. Prinz, ACS Nano 5, 5692 (2011).

${ }^{7}$ R. J. Gorte, S. Park, and J. M. Vohs, Nature 404, 265 (2000).

${ }^{8}$ P. D. L. Mercera, J. G. Van Ommen, E. B. M. Doesburg, A. J. Burggraaf, and J. R. H. Ross, Appl. Catal. 57, 127 (1990).

${ }^{9}$ P. D. L. Mercera, J. G. van Ommen, E. B. M. Doesburg, A. J. Burggraaf, and J. R. H. Ross, Appl. Catal. 71, 363 (1991).

${ }^{10}$ K. Tanabe, Mater. Chem. Phys. 13, 347 (1985).

${ }^{11}$ I. Denry and J. Kelly, Dent. Mater. 24, 299 (2008).

${ }^{12}$ D.-J. Kim, J. Eur. Ceram. Soc. 17, 897 (1997).

${ }^{13}$ Y. Natanzon, M. Boniecki, and Z. Łodziana, J. Phys. Chem. Solids 70, 15 (2009).

${ }^{14}$ M. H. Bocanegra-Bernal and S. D. de la Torre, J. Mater. Sci. 37, 4947 (2002).

${ }^{15}$ K. Castkova, H. Hadraba, and J. Cihlar, Ceram.-Silik. 48, 85 (2004).

${ }^{16}$ J. J. Swab, J. Mater. Sci. 26, 6706 (1991).

${ }^{17}$ G. H. Kenner, W. D. Pasco, J. T. Frakes, and S. D. Brown, J. Biomed. Mater. Res. 9, 63 (1975).

${ }^{18}$ S. Shukla, S. Seal, R. Vij, S. Bandyopadhyay, and Z. Rahman, Nano Lett. 2, 989 (2002).
${ }^{19}$ F. Namavar, C. L. Cheung, R. F. Sabirianov, W.-N. Mei, X. C. Zeng, G. Wang, H. Haider, and K. L. Garvin, Nano Lett. 8, 988 (2008).

${ }^{20}$ N.-L. Wu, T.-F. Wu, and I. A. Rusakova, J. Mater. Res. 16, 666 (2001).

${ }^{21}$ S. Jayakumar, P. V. Ananthapadmanabhan, T. K. Thiyagarajan, K. Perumal, S. C. Mishra, G. Suresh, L. T. Su, and A. I. Y. Tok, Mater. Chem. Phys. 140, 176 (2013).

${ }^{22}$ R. C. Garvie, J. Phys. Chem. 69, 1238 (1965).

${ }^{23}$ R. C. Garvie, J. Phys. Chem. 82, 218 (1978).

${ }^{24}$ A. Suresh, M. J. Mayo, W. D. Porter, and C. J. Rawn, J. Am. Ceram. Soc. 86, 360 (2003).

${ }^{25}$ Y. Cong, B. Li, S. Yue, D. Fan, and X. Wang, J. Phys. Chem. C 113, 13974 (2009).

${ }^{26}$ G. Štefanić and S. Musić, Croat. Chem. Acta 75, 727 (2002).

${ }^{27}$ M. J. Mayo, A. Suresh, and W. D. Porter, Rev. Adv. Mater. Sci. 5, 100 (2003).

${ }^{28}$ A. V. Singh, M. Ferri, M. Tamplenizza, F. Borghi, G. Divitini, C. Ducati, C. Lenardi, C. Piazzoni, M. Merlini, A. Podestà, and P. Milani, Nanotechnology 23, 475101 (2012).

${ }^{29}$ P. E. Scopelliti, A. Borgonovo, M. Indrieri, L. Giorgetti, G. Bongiorno, R. Carbone, A. Podesta, and P. Milani, PLoS ONE 5, e11862 (2010).

${ }^{30}$ S. Jaenicke, G. K. Chuah, V. Raju, and Y. T. Nie, Catal. Surv. Asia 12, 153 (2008).

${ }^{31}$ F. Namavar, G. Wang, C. L. Cheung, R. F. Sabirianov, X. C. Zeng, W. N. Mei, J. Bai, J. R. Brewer, H. Haider, and K. L. Garvin, Nanotechnology 18, 415702 (2007).

${ }^{32}$ S. Schlabach, D. V. Szabó, D. Vollath, P. de la Presa, and M. Forker, J. Alloys Compd. 434-435, 590 (2007).

${ }^{33}$ A. Ortiz, J. C. Alonso, and E. Haro-Poniatowski, J. Electron. Mater. 34, 150 (2005).

${ }^{34}$ H. Hahn and R. S. Averback, J. Appl. Phys. 67, 1113 (1990).

${ }^{35}$ P. Piseri, H. V. Tafreshi, and P. Milani, Curr. Opin. Solid State Mater. Sci. 8, 195 (2004).

${ }^{36}$ H. Haberland, M. Karrais, and M. Mall, Z. Phys. At. Mol. Clusters 20, 413 (1991).

${ }^{37}$ K. Wegner, P. Piseri, H. V. Tafreshi, and P. Milani, J. Phys. D: Appl. Phys. 39, R439 (2006).

${ }^{38}$ E. Barborini, P. Piseri, and P. Milani, J. Phys. D: Appl. Phys. 32, L105 (1999).

${ }^{39}$ H. V. Tafreshi, P. Piseri, G. Benedek, and P. Milani, J. Nanosci. Nanotechnol. 6, 1140 (2006).

${ }^{40}$ P. Piseri, A. Podesta, E. Barborini, and P. Milani, Rev. Sci. Instrum. 72, 2261 (2001).

${ }^{41}$ P.-E. Mazeran, L. Odoni, and J.-L. Loubet, Surf. Sci. 585, 25 (2005).

${ }^{42}$ A. Podestà, Development of protocols for a quantitative characterization of morphological and tribological properties of nanostructured films via the atomic force microscope, Ph.D. thesis (Università degli Studi di Milano, 2001).

${ }^{43}$ P. Colombi, I. Alessandri, P. Bergese, S. Federici, and L. E. Depero, Meas. Sci. Technol. 20, 84015 (2009).

${ }^{44}$ L. Rebuffi, J. R. Plaisier, M. Abdellatief, A. Lausi, and P. Scardi, Z. Anorg. Allg. Chem. 640, 3100 (2014).

${ }^{45}$ P. Riello, A. Lausi, J. Macleod, J. R. Plaisier, G. Zerauschek, and P. Fornasiero, J. Synchrotron Radiat. 20, 194 (2013).

${ }^{46}$ A. P. Hammersley, S. O. Svensson, M. Hanfland, A. N. Fitch, and D. Hausermann, High Press. Res. 14, 235 (1996).

${ }^{47}$ A. C. Larson and R. B. Von Dreele, General Structure Analysis System (GSAS) (Los Alamos National Laboratory Report LAUR 86-748, 2000).

${ }^{48}$ A. Podestà, F. Borghi, M. Indrieri, S. Bovio, C. Piazzoni, and P. Milani, J. Appl. Phys. 118, 234309 (2015).

${ }^{49}$ A.-L. Barabási and H. E. Stanley, Fractal Concepts in Surface Growth (Cambridge University Press, Cambridge, 1995).

${ }^{50}$ Dynamics of Fractal Surfaces, edited by F. Family and T. Vicsek (World Scientific, Singapore; River Edge, NJ, 1991).

${ }^{51}$ S. Tsunekawa, S. Ito, Y. Kawazoe, and J.-T. Wang, Nano Lett. 3, 871 (2003).

${ }^{52}$ S. Fabris, Acta Mater. 50, 5171 (2002).

${ }^{53}$ R. J. Borg and G. J. Dienes, The Physical Chemistry of Solids (Academic Press, 1992).

${ }^{54}$ K.-N. P. Kumar, K. Keizer, A. J. Burggraaf, T. Okubo, and H. Nagamoto, J. Mater. Chem. 3, 1151 (1993).

${ }^{55}$ K.-N. P. Kumar, Scr. Metall. Mater. 32, 873 (1995).

${ }^{56}$ G. Kresse and J. Furthmüller, Phys. Rev. B 54, 11169 (1996).

${ }^{57}$ A. Christensen and E. A. Carter, Phys. Rev. B 58, 8050 (1998). 